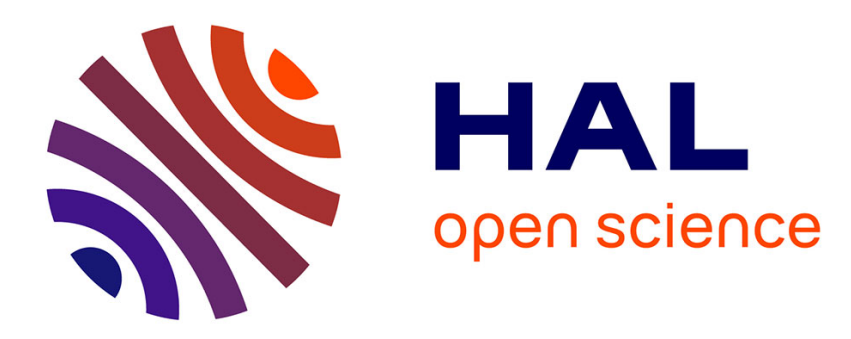

\title{
A Gate-Based Account of Intentions
}

Stéphane Lemaire

\section{To cite this version:}

Stéphane Lemaire. A Gate-Based Account of Intentions. Dialectica, 2012, 66, pp.45-67. 10.1111/j.1746-8361.2011.01287.x . hal-02972103

\section{HAL Id: hal-02972103 https://hal-univ-rennes1.archives-ouvertes.fr/hal-02972103}

Submitted on 26 Oct 2020

HAL is a multi-disciplinary open access archive for the deposit and dissemination of scientific research documents, whether they are published or not. The documents may come from teaching and research institutions in France or abroad, or from public or private research centers.
L'archive ouverte pluridisciplinaire HAL, est destinée au dépôt et à la diffusion de documents scientifiques de niveau recherche, publiés ou non, émanant des établissements d'enseignement et de recherche français ou étrangers, des laboratoires publics ou privés. 
This is an Author's Original Manuscript of an article published by Wiley in Dialectica 66.1, pp. 45-67 available online at DOI: $10.1111 / \mathrm{j} .1746-8361.2011 .01287 . x$

\title{
A Gate-Based Account of Intentions \\ Stéphane Lemaire
}

Université de Rennes 1

\begin{abstract}
In this paper, I propose a reductive account of intentions which I call a gate-based reductive account. In contrast with other reductive accounts, however, the reductive basis of this account is not limited to desires, beliefs and judgments. I suggest that an intention is a complex state in which a predominant desire toward a plan is not inhibited by a gate mechanism whose function is to assess the comparison of our desires given the stakes at hand. To vindicate this account, I rely on several considerations: the similarity between epistemic feelings and the feeling of being decided that tells us that we have an intention, the necessity of postulating a gate mechanism to explain our hesitating behavior, and the tight link that exists between the realization of our actions and our desires. In agreement with non-reductivists, I nevertheless acknowledge that intentions encompass plans, although I emphasize that the planning capacity must also be dependent on our motivational life and the general evaluative mechanisms that explains our emotions.
\end{abstract}




\section{Introduction}

Although it is now widely accepted that intentions constitute a sui generis and irreducible category of mental states, I would like to suggest that the dispute is worth reconsidering. Certainly, we must acknowledge that the complexity of intentions suggests a very convincing argument against reductive accounts in terms of beliefs, judgments and desires ${ }^{1}$. Indeed, non-reductivists ${ }^{2}$ have successfully shown that intentions have several complex functions or dimensions. Briefly, the first dimension is motivational: our intentions sustain our actions. Secondly, they have a monitoring dimension since they guide and control our actions. And finally, they trigger and constrain our practical reasoning. Since it seems impossible to explain these functions, in all their complexity, in terms of beliefs and desires, it has been said that we should adopt a non-reductivist account of intentions. Notice however that this argument is convincing only against reductive accounts that are exclusively in terms of beliefs and desires. Moreover, this complexity of intentions also gives us a prima facie reason to doubt that they constitute irreducible states. If a mental state or process is highly complex, then it becomes at first sight more plausible that it is constituted by several other states or processes that may, in other contexts, be exploited in other cognitive tasks. Admittedly, a single mental state can have several functions; a belief can for instance contribute both to our discourse and to

\footnotetext{
${ }^{1}$ More or less sophisticated versions of this idea appears in Audi (1973, 1991), Davidson (1978), Davis (1984), Grice (1971), Hampshire and Hart (1958), Harman (1976, 1986), Velleman (1985), Ridge (1998).

${ }^{2}$ Certainly, the works of Bratman $(1987,1999,2008)$ have been decisive. Versions of non-
} reductivism have been also proposed by Searle (1983), Brandt (1984), Mele (1992, 2003) and Pacherie $(2000,2006)$. 
our actions. But non-reductivist accounts of intentions are much more complex than that. Thus, one may wonder if this complex state is reducible, not to a set of beliefs and desires, but to a set of functionally organised states.

The aim of this paper is thus to develop such a reductive account, one that takes intentions to be identical to a combination of several states. This account is motivated by the idea that non-reductivists have isolated intentions too much from motivational life, as well as from the process that selects, from among all desires, those on which we act and from the mechanisms that constantly assess our situation and its outcomes.

The suggestion that I will defend is that an intention to $\mathrm{A}$ is a complex state in which a desire to $\mathrm{A}-$ where $\mathrm{A}$ is an action or a plan - is predominant and is not blocked by a mechanism whose function is specifically to inhibit in certain contexts our acting on predominant desires. I call this a gate-based reduction of intentions. This reduction thus encompasses not only a desire ${ }^{3}$, or a set of desires, but also an inhibiting mechanism and plans where these two latter elements are irreducible to beliefs and desires.

To develop this reductive account, I start in the second section from the indisputable fact that to have an intention to $\mathrm{A}$ is to be decided about doing $\mathrm{A}$, something that has to be distinguished from an event or an act of deciding. Analyzing the experience that one has when one is decided suggests that an intention may be a predominant desire that is not inhibited. I then pursue this proposal in the third section by arguing for the

\footnotetext{
${ }^{3}$ For simplicity, I suppose here that desires are the only motivational states if we leave apart intentions. Those who believe that some beliefs like moral beliefs are motivating have just to consider that desire is merely used here as a place-holder for any pro-attitude that is not an intention.
} 
existence of a gate-mechanism that has precisely this inhibiting function and by specifying its operating conditions. Thus I am led to the aforementioned gate-based reductive account: an intention is a predominant desire toward an action that is not inhibited by the gate-mechanism just uncovered.

However, an important objection against reductive accounts in terms of desires has been that intentions have a motivational function or dimension that cannot be understood in terms of desires because one may act on an intention even if the desires that originated the intention have weakened or disappeared. Hence, the argument goes, the motivational dimension of an intention is autonomous from the desires that contributed to its formation. By autonomous, I mean here that the motivational dimension of an intention to A does not necessarily correspond with our desire to A. If it is autonomous in this way, then it shows that the motivational dimension of our intentions is independent of our desires, that is, it is not ontologically constituted by desires. Finally, if the motivational dimension of our intentions is independent of our desires, then our intentions themselves cannot be reduced to a complex state encompassing desires. In the fourth section however, I show that this line of argumentation is far from convincing and that a gate-based reductive account along the lines proposed here is at least as good if not preferable for handling the alleged facts. Moreover, I also believe that this reductive account gives us a more realist view of the motivational power of intentions.

The last part of my account is then introduced in the fifth section in which I explain the role of plans in intentions: plans work in cooperation with the desires to realize triggering, guiding and controlling functions of intentions. Finally, in the sixth 
section, I explain how the other normative aspects of intentions are understood in the framework of the gate-based account presented here.

\section{Feeling decided and being decided}

According to a gate-based account, an intention to $\mathrm{A}$ is just a predominant and uninhibited desire to A where $\mathrm{A}$ is an action or a plan. In order to give some plausibility to this reductive account, in this section I start with what seems to me an uncontroversial claim: an agent has an intention to $\mathrm{A}$ if and only if this agent is decided to $\mathrm{A}$.

Before getting to an analysis of the state of being decided, it is important to distinguish it from the event or action of deciding. To begin, an explicit decision is not always required in order to be decided, a fact with which non-reductivists agree ${ }^{4}$. After days of hesitation, one might wake up one morning with the clear feeling of being decided. In such cases, the formation of an intention does not require any specific act of deciding. But in other situations, it seems that, on the contrary, the formation of an intention requires an act of deciding. This is very obvious when one needs to decide in advance between two options that seem equally attractive. We need to somehow tell ourselves what we will do for the intention to be constituted because without doing something like that we would not be decided. The precise nature of the mental act of deciding is a matter of much debate since it can be understood either as a sui generis type

\footnotetext{
${ }^{4}$ Bratman acknowledges that some intentions need not be deliberative and can be 'spontaneous' $(1987,57)$. Mele makes it even more clear that "not all intentions are arrived at via decision" $(1992,141)$.
} 
of act or as a linguistic act ${ }^{5}$. In any case, the important point for us here is that once one posits an act of deciding, it follows that these acts, like any other, may fail to achieve their goal. In other words, one may try to decide without thereby becoming decided and the reason for this failure may be that some motivational conditions are required for an act of deciding to succeed. This may explain why our deciding ${ }^{6}$ at random between equally attractive options often appears ineffective in producing a stable state of intending. Another case in point is one of an agent who is prone to compulsive verification behavior. Deciding to leave the house without coming back, the agent turns the key only to immediately reopen the door to check if the oven is turned off.

We can thus conclude that there is a double dissociation between the act of deciding and the state of being decided. We may become decided without having decided and we may try to decide without thereby becoming decided. However, this is not to deny that in most circumstances our acts of deciding are successful. They are successful precisely because we usually try to decide only when we believe that the conditions for our decisions to be successful are satisfied. In fact, this is a general truth about our actions. We rarely try to do something if we know that the conditions are such that we cannot succeed. I do not try to reach the phone if I know that I am not sufficiently close to it. Similarly, we most often try to decide when we believe that we already have a strong motivation and that the act of deciding will conduce to a state of being decided.

\footnotetext{
${ }^{5}$ Peacocke (2007) has defended the sui generis version and Carruthers (2007) relying on Frankish (2004) has defended the linguistic version.

${ }^{6}$ One may here be reluctant to call such an event a decision since a decision implies, in virtue of its very signification, that one becomes decided through that decision. But this objection is nullified by simple reformulation: "one may do what one usually does to make an explicit decision without becoming decided". Thus the dispute is merely semantic.
} 
Moreover, it is worth noting that even when our being decided is not the result of an act of deciding, it does not follow that our becoming decided is a purely sub-personal process. Certainly, numerous actions are undertaken and intended without any kind of active reflection or decision. However, our becoming decided without deciding may come out of a deliberative activity controlled or partly controlled at the personal level. If I become decided one morning after days of hesitation, it is probably because I also actively thought about the topic recently. It might even be impossible for me to become decided if I turn my attention away from the decision at hand. In any case, since our enquiry is on the nature of intentions, we will focus on the state of being decided rather than the act of deciding.

In order to understand the state of being decided, let us analyze from a phenomenological point of view our experience when we are decided. As we have already seen, we might wake up after days of hesitation with the conviction that we are decided, a conviction that seems grounded in a quite specific phenomenal experience. At first glance, we may describe this experience as a feeling of confidence about what to do that may be contrasted with the earlier feeling of uncertainty. The latter is often accompanied by hesitant behaviors or the feeling of being inhibited that may result either from fear about possible consequences or from the feeling that more deliberation is required given the stakes at hand. Notice, on the other hand, that we may experience a feeling of confidence even if we have important motivations against our intention. From a phenomenological point of view, we can clearly differentiate the situation in which we hesitate over strongly conflicting desires from the one in which we are firmly decided despite some strongly conflicting desires. That being said, it remains true that a strong 
opposition in our desires may itself contribute to our being undecided, and thus to a feeling of being undecided, but that is no argument against the distinction that I have pointed out.

It seems therefore that we experience being decided as a feeling of confidence about a disposition to act. Plausibly, we can categorize this feeling in contrast to the feeling that we have a strongly motivating, albeit inhibited, desire. But one may still be skeptical about this description and, beyond that, about the very existence of a feeling of being decided (henceforth FOBED). In order to respond to such doubts, I consider the general class of epistemic feelings and compare them with my description of the FOBED. My aim here is twofold. First, it is to strengthen the case for acknowledging the FOBED. If its description is such that it appears similar to the description of epistemic feelings that are now fully acknowledged, this would certainly be an argument in favor of the existence of the former feeling. In addition, drawing out these similarities may give us further clues about the nature of the FOBED and the state of being decided of which we become aware through the FOBED.

First, the set of epistemic feelings encompasses the feeling of knowing (henceforth FOK) that one may experience when one feels that one knows someone's name but is incapable of recalling it. It also encompasses the judgment that one has sufficiently worked to learn something (henceforth $\mathrm{JOL})^{7}$ and finally the feeling of certainty or uncertainty that one may experience with regards to one's own beliefs ${ }^{8}$. What is of interest for us is that the FOBED shares several features with them. The first one is

\footnotetext{
${ }^{7}$ For a survey of the research on FOK and JOL, see Koriat (2007).

${ }^{8}$ Cohen (1992) has insisted on the importance of these feelings. For a more recent discussion, see Carruthers (2008).
} 
obviously that these feelings make us aware of our possession of various mental states. The epistemic feelings tell us that we know a word, we learned a lesson or we have a belief. Similarly, the feeling of being decided tell us that we have an intention, that we are decided.

Second, Koriat $(2000,155)$ has shown that we should distinguish epistemic judgments that are grounded on consciously available information from epistemic judgments that are only grounded on an epistemic feeling or experience. This distinction is obvious when considering possible dissociations between these two kinds of judgments. When confronted with sufficient reasons to believe something, one might judge that it would be rational to acquire the corresponding belief in spite of feeling unconvinced. Similarly, despite having worked sufficiently to memorize something, one might still feel ignorant of what one is trying to memorize. What is of interest for us is that the same distinction must be made between the FOBED and the judgment that one would make from information that would normally imply that we are decided: one may have many reasons to be decided, and one may have even explicitly decided without feeling decided at all.

Third, it seems plausible that both epistemic feelings and their practical analogues are the result of behavioral and cognitive cues linked to dispositions to act. An interesting hypothesis about the "tip of the tongue" phenomenon is that it is a feeling linked to the behavioral disposition to deliver the name that one cannot recall. In the same way, the feeling of certainty about, say, the similarity of two pictures may be a manifestation of our disposition to assert this similarity. Koriat provides a good deal of empirical evidence to show that FOK and JOL rely on several indirect "mnemonic cues" such as "the ease or 
fluency of processing of a presented item, the familiarity of the cue that serves to probe memory, the accessibility of pertinent partial information about a solicited memory target, and the ease with which information is accessed" $(2000,158)$ and not directly on our memory traces themselves. Thus, it appears that these hypotheses converge with our description of the FOBED, for it seems quite plausible that the FOBED emerges similarly from behavioral cues, such as hesitating behavior or from muscular activity that reveals an action tendency, and also from cognitive cues, such as the ease with which we deliberate or the fluency of our cognitive processes while we envisage an action. I certainly know when I am undecided about what to do because I continue to deliberate intensely about the possible options. The behavioral and cognitive cues will then manifest in a state in which we are decided or undecided with regard to a plan or an action. Hence, they will allow us to know that we are decided or undecided. Again, the parallel is clear: both epistemic feelings and the FOBED are somehow experiences of dispositions to act, and both are grounded in behavioral and cognitive cues.

Fourth, it is believed that the role of epistemic feelings is to signal to oneself whether to persist in trying to remember a name or in learning a lesson. Since epistemic feelings indicates our epistemic states, it seems quite obvious that they will help us to decide what we should do with regard to questions of knowledge. But a very similar role may be ascribed to the FOBED: if we know that we are not decided, we thereby know that we still need to deliberate. Similarly, we have very different dispositions toward a project depending on whether we know that we are decided, firmly decided or, on the contrary, unable to become decided. As we have already seen, the consciousness of an act of deciding will never give us this information. 
From these analogies, several conclusions can be drawn. First, the close similarity between the description of FOK and JOL on one hand and my description of the FOBED on the other supports the idea that the FOBED really does exist - even if it is quite difficult to have a clear grasp of its nature - because it appears as a member of a larger family of phenomenon. Secondly, this similarity provides some support to the characterization of the FOBED as a state of confidence, a confidence towards a disposition to act as opposed to the feeling that a desire is strongly motivating, although inhibited. Finally - and this is crucial - if this is a correct description of the feeling of being decided, then it suggests an account of the underlying state of being decided as a state in which one has an predominant desire that is not inhibited. In other words, this account can be 'read off' from the phenomenology of being decided.'

\section{Introducing a gate-mechanism}

The phenomenological description of the FOBED given above suggests the following reductive definition of intentions: an agent has an intention to $\mathrm{A}$ if and only if the agent has predominant desires to A that are not inhibited. However, this reduction is plausible only if one can explain how predominant desires may be inhibited in reductive terms. In order to respond to this worry, I argue that it is necessary to postulate the existence of a gate-mechanism that is responsible for blocking (or not) predominant desires. In the process, I will specify how it functions, thus allowing me to detail my gatebased reductive account of intentions.

\footnotetext{
${ }^{9}$ I am grateful here to one of the anonymous referees who proposed this very suggestive presentation of my point.
} 
Let us start with the reasons to postulate an inhibitory mechanism. One reason derives from a well-known argument advanced by non-reductivists. They have rightly insisted that a predominant desire is not sufficient to have an intention. Whatever my desires, beliefs or judgments, I may still not have decided since "I might still be disposed to deliberate about what to do; for I might still not see the issue as settled." (Bratman 1987, 19). Moreover, even if I believe that the issue is settled, I may not see or feel that it is settled. A predominant desire to quit a job at a given time may be held back because one judges that a more extensive deliberation of the possible consequences would be appropriate or, more simply, because one just feels this way. Therefore, whatever makes a desire predominant at a given time, one must postulate a mechanism ${ }^{10}$ that can block my acting on it and trigger a more extensive deliberation.

The same point can be made by remarking that such a mechanism must be postulated in order to explain hesitating behaviors. We could not understand these behaviors if we were not endowed with a mechanism that inhibits our predominant desire. Moreover, there are evolutionary advantages to having a mechanism that prevents us from deciding and acting in situations in which the comparative evaluation of our desires is too superficial given the stakes at hand. Carruthers argues convincingly for this point by advocating for a "gate-keeping mechanism" that "will refrain from acting... and will initiate alternative information gathering behavior instead" $(2008,66)$ for very similar reasons. He argues that such a mechanism must be postulated in order to explain hesitating behaviors but also because it may be risky or irrational to act on a desire whose

\footnotetext{
${ }^{10} \mathrm{In}$ fact, this mechanism may be a sub-mechanism or a functional aspect of the mechanism responsible for our choices. For simplicity, I will however stick to this way of talking in the remaining of the paper.
} 
superior strength is insufficient or unstable, especially if this strength relies on an insufficient exploration of the consequences of the desire's realization. Although I fully agree that such a mechanism must be postulated, I would like to make several amendments about the rules that govern its functioning ${ }^{11}$.

First of all, such a mechanism may not intervene when the motivational difference of our desires is very small and if no negative consequence however slight can be anticipated: for instance, even if I have to choose between two similarly convenient dates for an appointment, I am not prevented from choosing between them since it does not appear to bear any negative consequences. Moreover, and as Bratman $(1987,11)$ has rightly pointed out, we must be able in ordinary contexts to choose between desires of similar strengths. If this were not the case, we would be blocked like Buridan's donkey as soon as we have two desires of equal strengths. We even sometimes need and are able to choose from two equally attractive options although we would prefer to have more time to deliberate on the decision to be made. Clearly, the same points must be extended to situations in which we would not have desires of equal strengths but only of similar strengths. Thus, a choice between desires of similar or equal strengths will not be blocked and will even be facilitated if no potential consequence looms or if it is beneficial to choose now.

Secondly, even if a desire is clearly predominant given the reasons under

\footnotetext{
${ }^{11}$ In fact and as it will appear, these amendments may only be relevant in the human case. The more simple operating conditions that Carruthers proposes may still be correct when applied to apes. More generally, one can envisage that the operating conditions of such a blocking mechanism will vary depending on the species on which we focus our attention. I thank Jérôme Dokic for pointing out this possibility to me.
} 
consideration, one might not act on this desire if fulfilling the desire causes certain negative consequences that have not yet been fully evaluated. As I have already noted, however, these last concerns may be overcome by the possible benefit that comes from our choosing now.

Thus, in order to take both of these considerations into account, I suggest that the gate-mechanism is not only a gate-blocking mechanism but also sometimes a gatefacilitating mechanism. That is to say that, on the one hand, this gate-mechanism blocks the fulfillment of a predominant desire (or of equally predominant desires) and triggers deliberation if a potential negative consequence is looming. On the other hand, it arbitrarily facilitates $^{12}$ the fulfillment of one of the equally predominant desires if no such consequence is looming.

There are at least two reasons to postulate a unique gate-mechanism. First, the condition for blocking or facilitating a choice presupposes an evaluation and comparison of the very same considerations, that is, of the relative strengths of the desired options and also of the results of a choice with potential negative consequences which deliberation may uncover. Second, a mechanism that can block - or prevent - a causal relation can often facilitate this same causal relation. Think for instance of a revolving gate, a propeller or more generally of most mechanisms that can regulate the flow of a liquid or a gas.

Thirdly, a point in favor of such a mechanism and of these operating conditions is that the conditions that trigger the gate-mechanism corresponds nicely with the following principle of practical rationality: even if one judges an action to be better than any other

\footnotetext{
${ }^{12}$ Notice that such a gate-mechanism need not have any influence on our desires. It may simply produce a predominant unblocked desire without reinforcing its strength.
} 
given a set of reasons considered, it is irrational to act on such a judgment if one believes that this set does not encompass, or at least reflect correctly, the set of relevant reasons ${ }^{13}$. Furthermore, this principle of rationality can be seamlessly extended to cases where it is rational to choose arbitrarily between actions for which we have equally good reasons, if one believes that they encompass, or reflect correctly, the set or relevant reasons.

The gate-mechanism thus explains from a functional point of view the difference between having a predominant desire to A and having an unblocked predominant desire to A. It allows us moreover to restate our proposed reduction of intentions: an intention to A is a predominant desire to A combined with the fact that the gate is open, either letting this predominant desire trigger our action, or facilitating the fulfillment of one of the equally predominant desires. To insist on the point, this is a reductive account because the disposition to act that constitutes an intention to $\mathrm{A}$ is not the disposition of an irreducible and single mental state but the coordinated effect of several states: a set of desires to A, its predominant status over other desires, the 'open' state of the gatemechanism whose function is either to block or to allow the fulfillment of desires in response to the evaluation of the quality of the comparison of our desires given the stakes at hand.

The preceding discussion leads us to the following clarification about predominant desires. Firstly, a predominant desire is only a desire which is at least as strong as those with which it is compared since one may have an intention to A even if one has another equally strong desire to B. Secondly, and more importantly, the notion of dominance, as we use it here, is relative to the set of desires that are taken into account

\footnotetext{
${ }^{13}$ Henden (2006) reminds us the importance of this principle for beings to whom the consideration of relevant reasons is costly.
} 
given a certain amount of deliberation or even the absence of deliberation at a given time. Therefore, a predominant desire need not be as strong as any other desire that we possess given a full and complete deliberation of all desires and their possible fulfillment. In fact, we are rarely in a position to make such a comparison. Given finite time for deliberation on one hand, and finite capacities to reflect on ways to satisfy and think about our desires on the other, the comparison of our desires (or between possible actions and plans) is partial, contextual and restricted to a small subset of our desires ${ }^{14}$. In addition, these limitations in comparing our desires explain why the possession of a gate-mechanism is crucial: even if the comparison of our desires is partial, it must not lead us to neglect what is of real importance. To recapitulate, a predominant desire is one that is at least as strong as the other desires being compared, in the context of a given deliberation.

To close this section, I would like to make an important point about prior intentions. This point concerns the temporality of the desires that constitute the motivational dimension of a prior intention on the gate-based reductive account. When one is decided, the predominant desires that are not inhibited are our present desires because being decided to A does not imply anything about my future desires to A. In particular, I can have the prior intention to work this afternoon even if I am nearly sure

\footnotetext{
${ }^{14}$ I make here the hypothesis that the set of desires to which a desire is compared when we choose depends on the internal context of our thought and state of mind. If we deliberate, the extention of this set depends precisely on the extension and orientation of our deliberation. However, if we do not deliberate, it seems reasonable to believe that several desires are still often competing for predominancy even if the desires compared are not conscious.
} 
from my behavior over the last few days that I will not be motivated this afternoon and that I will not work at all ${ }^{15}$. Nevertheless, as I am now decided, I am presently disposed to act immediately in order to realize this plan or against other plans that would be incompatible. I may, for instance, refuse an invitation to go to the movies. Therefore, a prior intention to $\mathrm{A}$ at a future time $\mathrm{t}$ encompasses a present predominant desire to $\mathrm{A}$ at $\mathrm{t}$ but not a future predominant desire to A nor a predominant desire to A now. An intention to $\mathrm{A}$ is a predominant uninhibited desire to A now only if it is an intention to A now.

This explains in part how a gate-based account applies to prior intentions. Since a prior intention is an uninhibited predominant desires to $\mathrm{A}$ at $\mathrm{t}$ in the future, the fact that the desire is uninhibited does not imply that we are going to act on it now since it is only a desire to act in the future. We shall however say a bit more on this point at the beginning of the fifth section which concerns the guiding role of plans.

\section{The motivational dimension of prior intentions}

The introduction of the gate-mechanism allows us to explain how one can have a predominant desire without being decided, and therefore without having an intention. It thus deprives the non-reductivist of one of its major arguments against reductivism. However, non-reductivists have also insisted that the formation of an intention can lead us to act, even if the desires that gave rise to our intentions have become weaker or

\footnotetext{
${ }^{15}$ Notice however that this is compatible with the impossibility of having an intention to A if I believe that it is absolutely impossible to $\mathrm{A}$. This last impossibility may moreover be derived from the fact that I will have no desire to A if by desire I understand the desire multiplied by the probability of realizing A which is here supposed to be null.
} 
disappeared. For instance, Bratman holds that "prior intentions and plans can have an independent role in rational motivation: once in place they can sometimes rationally control conduct even in the face of a temporary preference change to the contrary." (Bratman 1995, 304). Similarly, Holton writes, "Intentions can thus work to preserve the motivational power of earlier desires: a desire can give rise to an intention, and this intention can result in subsequent action even when the desire is no longer present. Indeed an intention can result in subsequent action even when there are, by that time, contrary desires present." $(2003,48)$. In other words, since the motivational force of an intention is not identical to that of our desires, it follows that the motivational dimension of intentions is independent of our desires, i.e. not constituted by desires. Interestingly, Mele draws out the consequences of this view very explicitly by generalizing this independence thesis even to cases in which our desires have been stable. He states: "It may normally happen that desires to A play a causal role in the production of intentions to $\mathrm{A}$ and that the desires persist at least as long as the intentions do. When this happens, the agent who intends to A does desire or want to A, even if the intention does not have the desire or want as a constituent." (Mele 2003, 171, emphasis is mine). The argument of the non-reductivists is thus that the motivational dimension of my intentions is not always in line with our desires. This motivational dimension has some autonomy from desires. Therefore, it is ontologically independent of our desires; it is not constituted by any of our desires.

Notice however that the defense of this ontological independence does not preclude one from acknowledging that, at least in general, our desires 'play a causal role' or 'give rise' to our intentions. In fact, both reductivists and non-reductivists agree that 
the motivational dimension of an intention is causally derived mainly from those desires that led to forming the intention. No one defends the view that the motivational power of intentions is not inherited from our desires. However, beyond this causal dependency of the motivational dimension of intentions on desires, I have already mentioned that, for the non-reductivist, once an intention is formed, its motivational dimension becomes autonomous, a fact that is explained, so they say, only by acknowledging that it is independent of our desires or equivalently that the motivational dimension of our intentions is not constituted by desires.

It is thus clear that the non-reductivist's claim - that the motivational power of an intention to A may not be in line with, or has some autonomy from, our desires to A - is meant to advocate strongly for their view. However, I believe that we have reason to be doubtful of this supposed fact. I have here two complaints. First, it seems to me that nonreductivists do not pay enough attention to the numerous cases in which the motivational dimension of our intention is in fact in line with our desires, even when those desires have evolved since we formed our intention. Second, even when the motivational dimension of an intention is more stable than the desires that contributed to its formation, this does not preclude any explanation of this fact that would maintain that the motivational dimension of our intentions is constituted by desires and by desires only. Let's consider these two points in turn.

My first complaint is that non-reductivists do not pay enough attention to the changes that the motivational dimension of an intention may undergo. Consider the following example. I thought that it would be a great idea to cycle to my office and I embrace this plan with enthusiasm. However, the next morning I no longer feel the same 
enthusiasm. I nevertheless cycle to my office without reconsidering my intention. I pick up my bicycle without any enthusiasm; this makes my trip seem especially tedious precisely because of my lack of enthusiasm and so, I grumble the whole way. Now, we might ask, "What motivated me to cycle to my office?" It seems to me that the most natural answer is that I was motivated by my desires, and that it is precisely because my desires had become less important that I grumbled all the way. Consider the contrary interpretation, according to which the motivational dimension of the prior intention is responsible for my action and inherits the force of my past enthusiastic desire. But if the motivational dimension of my intention were unaffected by the evolution of my desires, then surely I would have acted with more enthusiasm or determination. At the very least, the motivation that kept me cycling would have been stronger and would have given me more energy, influencing my style of cycling. Thus, it seems more plausible that the motivational dimension of an intention to $\mathrm{A}$ is not autonomous from the desires to $\mathrm{A}$ and the best explanation of this lack of autonomy is that the motivational dimension of an intention to $\mathrm{A}$ is constituted by the desires to $\mathrm{A}$.

The non-reductivist may however deny that the motivational dimension of my intention itself has evolved, instead suggesting that it is only the expression of my motivation that is different. To some extent, I concede that such dissociations exist. After all, even if my desires do not change, my enthusiasm when I make my decision may be replaced by an intense concentration when time comes to go through with what I decided. Notice that there is nevertheless still a correlation between our first enthusiasm and our later determination.

However, even if this response is defensible in this one example, it does not 
generalize to other cases. Imagine that someone decides to make her colleague aware of a serious business mistake he is about to make, and that she clearly comes to this decision out of sympathy for him, and thus out of a desire to help him. But because of the exasperating way that he talks about a friend of hers, when she finally come to tell him of his mistake, she does so with great violence - as if as an appropriate response to his attack on her friend. Here, two things are clear. First, it is quite obvious that her initial sympathy and later anger are not linked to the same motivational state: at first she has a desire to help but then this desire is superseded by a desire to retaliate. Second, when she acts on her intention, its motivational dimension is in line with her new desire to retaliate and not with the desire to help that she had when she formed the intention, as the way in which she finally fulfills her intention shows. Thus the motivational dimension of intentions is not autonomous from desires since the evolution of the former follows the evolution of the latter.

In response to this objection, the non-reductivist may insist that although the motivational dimension of intentions is not autonomous from our desires, it is nevertheless independent from our desires as an ontological fact. This is a plausible line of argument, but at this point the burden of the proof shifts to the non-reductivist. If the motivational dimension of our intentions evolves as our desires do, then the nonreductivist must explain why we should hold that the motivational dimension of intentions is not constituted by our desires since it is obviously the simplest solution. Moreover, the non-reductivist must also explain the mechanism that changes the motivational dimension of our intentions as our desires change. In any case, the nonreductivist has provided no argument up to now against the gate-based reductive account. 
A better strategy for the non-reductivist is therefore to point out that the motivational dimension of an intention to $\mathrm{A}$ is in fact not always fully in line with our desires. Indeed, non-reductivists have emphasized that our intentions allow us to resist the evolution of our desires as we have already seen. This seems especially conspicuous when one is able to resist temptation precisely because one has formed a prior intention to do so. Therefore, intentions include an element of inertia (or stability or settledness) that our desires lack and which makes the motivational dimension of our intentions autonomous from our desires. This is a serious argument against any reductive account in terms of desires. However, I contend that there is another explanation for this inertia that is compatible with any reductive account in terms of desires, one that is moreover as plausible as the one given by non-reductivists. The general point of this other explanation is that when one forms an intention to A, desires to A are reinforced.

One element is that going back on a decision will lead me to conclude that I am someone who does not stick to decisions. Most of us - even if to varying degrees would prefer not to draw such an unpleasant conclusion ${ }^{16}$. For instance, if I announce to my colleagues that I'm going to finish this paper this summer, the effect is very obvious I will be more motivated to finish - and it persists even if I am the only witness to my decision. Such an effect may also occur if an intention is not formed as a result of a decision. The simple fact of having a lasting intention may produce a feeling of investment through a process of identification with that intention. Hence, in both cases, my intention to A will be sustained by a new and supplementary desire to A. This

\footnotetext{
${ }^{16}$ Sobel $(1994,250)$ argues similarly that an agent may value that one follows through with one's decisions (or "get a bonus" using the language of Sobel). In consequence, as soon as one has made a decision one has a supplementary motivation to follow through with this decision.
} 
supplementary desire to $\mathrm{A}$ is the result of one of two processes: it derives either instrumentally from the desire to be the type of person who sticks to decisions in addition to the belief that one formed a decision to A, or it derives from the progressive selfidentification with one's intention to A that adds some strength to the original desires to A.

Secondly, to maintain an intention until time comes to act implies renouncing other lines of conduct or taking some preliminary actions. Intentions often cost us something before they produce any benefit. Here, we recognize the well-studied phenomenon of 'sunk cost' or 'escalating commitment', which is a tendency to invest more in a strategy after an initial investment than one would have if one had known from the outset the full cost of the strategy ${ }^{17}$.

Finally, one decides things because there is often a benefit to be gained from being decided in advance. For instance, it allows one to be calmer when the time comes to act, or better prepared and organized. It appears then that sticking to a decision often implies a benefit — and a supplementary motivation to act as decided - which would be lost if one were to change one's mind.

To sum up, the inertia of an intention to A that apparently allows us to act against our predominant desires can in fact be fully explained by the production of new instrumental desires to A derived from several other desires and from the acknowledged fact that these desires will be satisfied only if we fulfill our prior intention to A. In other

\footnotetext{
${ }^{17}$ Staw (1976) has shown that the phenomenon is experimentaly robust even if there is no agreement on an explanation of the phenomenon. For a discussion of possible explanations, see for instance Whyte (1986). I am indebted to Sasha Bourgeois-Gironde who pointed out this trend in the research to me.
} 
words, on this view, the motivational dimension of a prior intention to A is fully constituted by our desires to A, whether these desires are originally desires to A or instrumental desires to $\mathrm{A}$ where the accomplishment of $\mathrm{A}$ is a means to fulfill a distinct desire, like the desire to act on decisions that have been taken in advance or the desire to be a person who sticks to decisions.

In addition, these new instrumental desires, partly produced by the formation of a prior intention, explain why a prior intention implies not only a rational commitment but also supplementary motivations in accordance with this commitment. The rational commitment derives from the fact that if there is an interest in being decided in advance, then it becomes rational to form intentions in advance and to stick to them to some extent since it is only by sticking to them that one is able to profit from this anticipated decision. On the other hand, the supplementary motivations to stick to this commitment are nothing other than the instrumental desires to fulfill an intention that are produced by the very formation of this intention.

Once again, it is important to note that the different explanations given by the non-reductivist and the one that we have just presented are not on equal footing. The explanation of inertia just given relies on motivational factors that one must acknowledge whether one is attracted to a non-reductivist account of intentions or not. There is, in other words, already an explanation of inertia. Hence, the only remaining question is whether we need to postulate, on the top of that, sui generis intentions - and more precisely, sui generis intentions with a motivational dimension that is independent and more stable than the desires that contributed to their formation. 
To summarize, considering the motivational dimension of intentions does not give support to non-reductivist accounts. As we have seen, the non-reductivist has first neglected to pay attention to the numerous situations in which it is quite obvious that the changes of the motivational dimension of our intention are in fact congruent with the changes of our desires. Although they can account for this, their explanation of this fact is not the most direct since they have to postulate a mechanism that explains why we act on motivations that are similar to our desires but are not our desires. Secondly, the phenomenon of inertia is already explained in terms of desires. Thus, once again the introduction of non-reductive intentions is unnecessary. It appears that in both cases the non-reductivist introduces something that is not required to explain the phenomena. Therefore, far from introducing an objection against a reductive account, analyzing the motivational dimension of intentions shows that the burden of proof falls squarely on the non-reductivist. In other words, the upshot of this discussion is that the fulfillment of our intentions does not rely on a motivational dimension of our intention that is autonomous or partly autonomous from our desires. And from there, it follows that it is more plausible to suggest that the motivational dimension of an intention to $\mathrm{A}$ is constituted by our desires to A. Although it might have been beneficial, from an evolutionary point of view, that the motivational dimension of intentions is autonomous from our desires as Bratman often $_{\operatorname{argues}}{ }^{18}$, it seems that we are not built that way. In fact, it is precisely because we are built as we are that our actions are sensitive, for better or for worse, to all the

\footnotetext{
${ }^{18}$ Bratman $(1995,304)$. The thesis that it is advantageous to stick to our intentions is itself far from obvious. For instance, it would be completely inappropriate to do something dangerous that we decided yesterday if we lack confidence and feel moody today.
} 
variations of our desires even if these variations appear after we have already started fulfilling our intention.

\section{The triggering, guiding and controlling functions of intentions}

Any reduction of intentions will remain unsatisfying if it is unable to explain how our intentions trigger, guide and control their fulfillment. In fact, this "executive" dimension of intentions has been a major argument for non-reductivists who have been tempted to conclude that if we have an irreducible planning capacity that allows plans to trigger, guide and control their realization, then it follows that any reductive account of intentions is mistaken. Bratman summarizes this point well, saying that intentions are "conductcontrolling pro-attitudes" whereas ordinary desires are "merely potential influencers of action" (Bratman 1987, 16). But this argument shows only that a successful reductive account has to explain how intentions trigger, guide and control the actions that figure in their content. Furthermore, even if this function of intentions must rely on plans that may be irreducible, it does not prove that intentions are therefore irreducible - a line of argument that often seems implicit to Bratman's 'planning theory of intentions' (ibid., 10). The reason is simply that intentions may be complex states that encompass both plans and desires. Of course, intentions would be irreducible if they were nothing other than plans, but this last view is clearly wrong since one can consider a plan, for instance how to get to the closest bakery, without having the intention to go through with this plan. One might consider it only to tell someone else how to get there. 
The foregoing argument shows that a plan is not in itself sufficient to constitute an intention since it may not be motivating. On the other hand, it is hard to dispute that if I form the intention to get to the closest bakery, the plan just mentioned is going to play an irreducible role in triggering, guiding and controlling the fulfillment of my intention. Indeed, showing this has been a major contribution of non-reductivist accounts of intention. But fortunately, these two latter points are compatible: the gate-based reductivist can agree that plans trigger, guide and control the successive actions that constitute the plan but that they do so only if these plans are the content of predominant uninhibited desires. Therefore, we need not stray from the account proposed so far: intentions are predominant uninhibited desires. We just need to specify two points. First, the content of the desires must be a plan even if it might only be an action in the simplest cases. Second, it is only when a plan is the content of predominant uninhibited desires that it will play its triggering, guiding and controling functions. This obviously implies that an intention is a complex state encompassing at least a predominant uninhibited desire and a plan, but it is not the simple sum of these two states since they form an intention only when the plan is the content of the desire. It is then that a plan triggers, guides and controls the successive steps that constitute the plan. This is why I maintain the previously mentioned formulation of my reduction of intention as uninhibited predominant desires toward a plan since it expresses more conspicuously the complex structure of intentions that encompass both desires and a plan but also their specific relationship. 
However, one may wonder whether this proposal is really defensible: can such a view of intentions really give us a satisfying account of the triggering, guiding and controlling functions of intentions that non-reductivists spell out?

A first point is that the introduction of plans in our account helps us to see how our reduction applies to prior intentions. Certainly, one may wonder how this gate-based account in terms of uninhibited predominant desires applies to prior intentions. If prior intentions are intentions on which we are not acting now, mustn't their motivational dimensions be inhibited? It seems they must. However, the apparent contradiction disappears as soon as we make a distinction between, first, the gate mechanism within an intention whose function is to inhibit (or not) predominant desires and, second, the plan, one of whose functions is to trigger our actions at the right moment (and therefore to otherwise inhibit our actions). When open, the gate mechanism is the one in conjunction with which a predominant desire is an intention, whether this intention is a motor, present or prior intention. However, even if this gate mechanism is open in advance as with prior intentions, the realization of this prior intention is only triggered at the relevant moment in accordance with the plan. Notice that this is precisely how we experience our acquiring of a prior intention: we feel that we are no longer blocked or prevented to act although we will only fulfill our intention later. Thus, if we are careful to distinguish the inhibiting role of the gate mechanism and the triggering role of plans, we see how our analysis of intentions applies not only to motor and present intentions but also to prior intentions.

Having established this important point, we move on to show how this account explains the triggering, guiding and controlling functions of intentions. In what follows, I distinguish the representational and motivational aspects of the guidance and control 
functions of intentions. If we first concentrate on what I will call the function of representational guidance of intentions, we can simply import what the non-reductivists themselves say: plans perform their triggering, guiding and controlling functions by the activation of a downward hierarchy of embedded plans that terminates in the motor plans that directly cause our movements. The central element that differentiates our gate-based account is just that these plans perform these functions only if they constitute the content of predominant uninhibited desires. As a consequence, the desires that sustain a plan also play a role of motivational guidance. The desires that constitute the motivational dimension of an intention contribute in selecting the means that we employ to realize a plan. As we have shown in the previous section, even at the lower level, the specific way in which we realize a plan depends on the desires that sustain this plan as we act. The specific desires that we have and their strengths influence the selection of appropriate movements and even their dynamic character. Moreover, depending on whether an agent desires a goal intensely or not, or on whether the agent is of two minds or not, the very same action will be performed differently. These are all consequences of the discussion in the last section. Thus, the guiding function of our intentions is a combined effect of our plans on one hand and of the desires that take them as their content on the other.

But what of the controlling function of intentions? As for the guiding function, I suggest that the fulfillment of this function is the combined effect of the plan and of the predominant uninhibited desires that constitute an intention. Again, we can distinguish representational from motivational aspects of this controlling function. On one hand, plans have a representational controlling function because the accuracy of the realization of a plan is evaluated relative to the plan itself. Again, our reductive account does not 
differ here from the non-reductivist's since we integrate plans and their controlling function as described by non-reductivists when they constitute the content of uninhibited predominant desires. On the other hand, non-reductivists have rightly underlined that intentions also exercise a motivational control that evaluates the side effects of accomplishing the plans that constitute their content. This control in turn may affect the motivational dimension of intentions by weakening, strengthening or stopping them (Pacherie 2006, 152) ${ }^{19}$. In order to explain how this motivational control is produced, non-reductivists have postulated a specific process that evaluates the consequences of our intentions as we realize them; the result of this evaluation may change the motivational dimension of intentions themselves. However, I believe that our gate-based reductive account offers a preferable explanation of this motivational control.

To begin with, it is worth emphasizing that this evaluation must be relative to our goals, our motivational dispositions in general and our desires. Hence, it is not as if this control and evaluative function could work in isolation from our desires. Secondly, there is already a general evaluative process that assesses our past, present and future; it is the evaluative process that underlies all of our emotions. Moreover, we know by experience that, when in the process of deliberation, even the mere consideration of a desire and its possible consequences triggers emotions. It is then no mystery that this general evaluative

\footnotetext{
${ }^{19}$ In fact, Pacherie suggests that this motivational control (collateral control in the words of Pacherie) characterizes only present and motor intentions, but I do not see why we should deny this kind of control to our prior intentions. After all, when I form a prior intention, I form it by reflecting on its consequences and side effects and in having this intention, I am certainly more sensitive to new facts that may alter the opportunity to keep/ stay with/ this intention.
} 
process will assess what we are about to do (or what we do and its possible consequences), especially given that our attention is focused on this future. Finally, it is now generally admitted that the emotions that come from the general and continuous evaluation of our situation affects our motivational life by producing new desires or by modifying our present desires ${ }^{20}$.

The upshot is that our gate-based account is not only capable of explaining the motivational side of the controlling function of an intention and its effects on this very motivational dimension but it is also more economical and better integrated with other aspects of our cognitive system for two reasons. Firstly, since this motivational control is already explained as the mere application of a general evaluative process, it is pointless to make the further claim that intentions rely on a very specific mechanism of evaluation devoted to intentions. Secondly, according to my view, the evolution of the motivational dimension of our intentions turns out to be nothing other than the evolution of the desires that constitute the motivational dimension of an intention, an evolution that we must in any case acknowledge as the effect of the general evaluative mechanism that underlies our emotions.

To summarize, if intentions are predominant uninhibited desires with plans as their content, then we are able to give a full account of the guiding and controlling functions of intentions as the combined effects of the desires and plans that they

\footnotetext{
${ }^{20}$ The most developed and plausible models of emotional processes imply at their core an appraisal or evaluation of our past, present and future situations in relation to our goals, interests and desires. For an overview, see Scherer et al. (2001). Moreover, Frijda's work (1986) has brought about wide agreement that these appraisals and emotional processes influence our motivations.
} 
encompass. While the plan, when sustained by predominant uninhibited desires, is responsible for the representational guidance and for accuracy control, the desire's guiding function is to select the subparts of the plan that guide its realization. Finally, the motivational control is produced by the general evaluative system that is responsible for our emotions when applied to an envisaged goal, consequence, or side-effect. This system evaluates the envisaged goal, consequence, or side-effect and consequently modifies our desires. In this way, it may modify the motivational component in the gate-based reductive account of intentions since it is constituted by desires.

\section{Normativity}

Now that the gate-based account has been fully presented, we must ask whether it can satisfactorily explain the normative role of intentions beyond their monitoring dimension.

There remain two normative aspects of intentions to be discussed. One bears on their role in practical reasoning, and the other is about the specific commitments that intentions imply. Concerning the first, there are two sub-points to consider. First, we have already seen that our intentions play a constraining role in our practical reasoning since it is irrational to hold incompatible intentions. In fact, in our framework, this normative constraint is part of the operating conditions of the gate mechanism. As we have seen, these operating conditions are such that a predominant desire is blocked if it threatens important desires or concerns. But if our intentions are predominant uninhibited desires and if they are sufficiently strong, then it follows that they will inhibit other predominant desires in the present context. If, on the contrary, they are not sufficiently strong, then the 
new predominant desire will not be inhibited and thus it will supersede the old one. In other words, an intention will block the formation of incompatible intentions unless we revise this very intention to form a new one based on the present predominant desire. Notice that on the contextual account suggested here of what constitutes a predominant desire, the evolution of our desires may not be sufficient for cancelling an intention or for an intention to supersede a previous one. To some extent, for such a change to have these consequences, it is necessary that this change causes the gate mechanism to inhibit the previous predominant uninhibited desire either directly or through a new deliberation that may in turn produce a new intention. Thus the gate-based reductive account has a further means to explain why the reversal of our desires in themselves do not constitute an immediate change to our intentions.

Second, intentions trigger practical reasoning and motivate us to find means of realizing our plans. This is nevertheless easily explained thanks to our reductive framework: if an intention to $\mathrm{A}$ is a present predominant uninhibited desire to $\mathrm{A}$, then this desire implies a disposition to search at the appropriate time for the means to realize A. In reality, it is plausible that any desire encompasses a disposition to look for the means to realize this very desire. But because this desire is predominant and uninhibited in the case of intentions, this disposition will be strengthened.

Finally, let us come to the commitment that intentions seem to imply. To begin with, it is important to acknowledge that there has been an important debate about this topic and that it is far from resolved. It seems thus that this aspect of intentions does not give us strong facts of the matter that any account of intentions should agree with. Furthermore, there is no agreement even between non-reductivists on the extent of this 
commitment. Gauthier (1994) for instance defends a very strong view of this commitment since he asserts that it is rational to have an intention and to fulfill a plan even if at some point of its fulfillment it would be irrational from an instrumental point of view to go through with it whereas Bratman (1998) rejects such a violation of instrumental rationality. Nevertheless, reductivists are certainly driven to adopt a quite modest view of this commitment such that it derives only from instrumental rationality. My view is simply that the formation of an intention produces no supplementary commitment beyond the rational benefit of planning and anticipation. Now, from a motivational point of view, it is easy to see how the account presented here can explain how this modest commitment may have some force. The explanation derives again from instrumental rationality and from the gate-mechanism: we are motivated to realize our intention because the advantage of being decided in advance would be lost if we change our mind and because there may be no visible reason to trigger a deliberation that may supersede our predominant desire. This motivation, I acknowledge, may be of little force in the case of a serious motivational reversal. However, several irrational motivations such as the desire to be a person who sticks to decisions may produce some additional instrumental motivation to fulfill intentions, as we have shown in the fourth section.

\section{Conclusion}

In this paper, I have proposed a new reductive account of intentions. On this gate-based account, an intention to $\mathrm{A}$ is a set of predominant and uninhibited desires to $\mathrm{A}$, where $\mathrm{A}$ is a plan or at least an action. It is a complex state that encompasses a set of desires that 
are predominant, a gate mechanism in an open state whose function is to assess the quality of the comparison of these desires given the stakes at hand and finally a plan that is the content of the predominant desires. I have argued that four considerations support this account. First, the phenomenology of the feeling of being decided corresponds to such a gate-based reductive account. Secondly, I have shown that a gate mechanism with particular operating conditions must be posited in order to explain our hesitating behaviors as well as our ability to choose among equally attractive options, and this proposal also concurs with our account. The gate mechanism also allows us to explain straightforwardly why a predominant desire is not already an intention. Thirdly, a proper understanding of the motivational dimension of intentions is in favor and not against a reductive account in terms of desires. Moreover, I have shown how this reductive account can easily explain both the inertia of intentions and the commitment that they imply, whether our motivations to fulfill this commitment are derived from rational or irrational considerations. Fourthly, I have shown that this reductive account can explain the ability of intentions to guide and control their realization since our reduction integrates plans, with the qualification that these functions of intentions are the intermingled effects of the plans and of the desires that take them as their content.

Clearly, none of these arguments are definitive. However, I have shown that several aspects of intentions and of their relations with other states and processes have been heretofore underestimated. Since integrating them constitutes a serious challenge for 
the non-reductivist, the gate-based reductive account may not only be plausible but, in the end, preferable.*

\footnotetext{
* I am grateful to Christine Tappolet, Elisabeth Pacherie, and especially Jérôme Dokic for their very helpful comments on several drafts of this paper. I would like also to thank the anonymous referees of Dialectica and Felicity Bodenstein and Kousaku Yui for their linguistic help.
} 


\section{References}

Audi, R. 1973, "Intending”, The Journal of Philosophy 70, pp. 387-403

Audi, R. 1991, "Intention, Cognitive Commitment, and Planning", Synthese 86, pp. 361378

Bach, K. 1978, “A Representational Theory of Action”, Philosophical Studies 34, pp. $361-379$

Brand, M. 1984, Intending and Acting, Toward a Naturalized Action Theory, Cambridge, Mass.: MIT Press

Bratman, M. E. 1987, Intentions, Plans, and Practical Reason, Cambridge, Mass.: Cambridge University Press

Bratman, M. E. 1992, “Planning and Temptation”, in: L. May, M. Friedman and A. Clark eds., Minds and Morals, Essays on Ethics and Cognitive Sciences, Cambridge, Mass.: MIT Press, pp. 293-310

Bratman, M. E. 1998, "Toxin, Temptation, and the Stability of Intention”, in: J. L. Coleman and C. W. Morris, eds., Rational Commitment and the Social Justice: Essays for G. S. Kavka, Cambridge, Mass.: Cambridge University Press, pp. 59-83

Bratman, M. E. 1999, Faces of Intentions, Cambridge, Mass.: Cambridge University Press

Bratman, M. E. 2007, Structures of Agency, Oxford: Oxford University Press

Carruthers, P. 2007, “The Illusion of Conscious Will”, Synthese 159, pp. 197-213

Carruthers, P. 2008, "Metacognition in Animals: A Skeptical Look", Mind and Language 23,pp. 58-89 
Cohen, L. J. 1992, An Essay on Belief and Acceptance, Oxford: Oxford University Press

Davidson, D. 1978, “Intending”, in: D. Davidson, Essays on Actions and Events, Oxford: Oxford University Press, pp. 83-102.

Davis, W. A. 1984, “A Causal Theory of Intending”, American Philosophical Quarterly 21, pp. $43-54$

Frankish, K. 2004, Mind and Supermind, Cambridge: Cambridge University Press

Frijda, H. H. 1986, The Emotions, Cambridge, UK: Cambridge University Press

Gauthier, D. 1994, “Assure and Threaten”, Ethics 104, pp. 690-721

Grice, H. P. 1971, "Intention and Uncertainty”, Proceedings of the British Academy 57, pp. $263-79$

Hampshire, S. and Hart, H.L.A. 1958, “Decision, Intention, and Certainty”, Mind 67, pp. $1-12$

Harman, G. 1976, "Practical Reasoning”, Review of Metaphysics 29, pp. 431-63

Harman, G. 1986, "Willing and Intending”, in: R. Grandy and R. Wagner, eds., Philosophical Ground of Rationality, Oxford: Clarendon Press, pp. 363-380

Henden, E. 2006, “The Role of All Things Considered Judgements in Practical Deliberation", Philosophical Explorations 9.3, pp. 295-308

Holton, R. 2003, "How is Strength of the Will Possible ?”, in: S. Stroud and C. Tappolet, eds., Weakness of the Will and Practical Irrationality, Oxford: Clarendon Press

Israel, D., Perry, J. and Tutyia, S. 1993, “Executions, Motivations and Accomplishments", Philosophical Review 102, pp. 515-540

Koriat, A. 2000, “The Feeling of Knowing: Some Metatheoretical Implications for Consciousness and Control”, Consciousness and Cognition 9, pp. 149-171 
Koriat, A. 2007, “Metacognition and Consciousness”, in: P. D. Zelazo, M. Moscovitch and E. Thompson, eds., Cambridge Handbook of Consciousness, New York: Cambridge University Press, pp. 289-325

Mele, A. R. 1992, Springs of Action, Oxford: Oxford University Press

Mele, A. R. 2003, Motivation and Agency, Oxford: Oxford University Press

Pacherie, E. 2000, “The Content of Intentions”, Mind and Language 15.4, pp. 400-432

Pacherie, E. 2006, “Toward a dynamic theory of intentions”, in: S. Pockett, W. P. Banks, W. and S. Gallagher, eds., Does Consciousness Cause Behavior? An Investigation of the Nature of Volition, Cambridge, Mass.: MIT Press, pp. 145-167

Peacocke, Ch. 2007, "Mental Action and Self-Awareness (I)", in: J. Cohen and B. McLaughlin, eds., Contemporary Debates in the Philosophy of Mind, Oxford: Blackwell, pp. $358-376$

Ridge, M. 1998, “Humean Intentions”, American Philosophical Quarterly 35, pp. 157178

Scherer, K. R., Schorr, A. and Johnstone, T. (eds.) 2001, Appraisal Processes in Emotion, Oxford: Oxford University Press

Searle, J. R. 1983, Intentionality, Cambridge; Mass.: Cambridge University Press

Sobel, J. H. 1994, Taking Chances: Essays on Rational Choice, Cambridge, Mass.: Cambridge University Press

Staw, B. 1976, "Knee-deep in the big muddy: A study of escalating commitment to a chosen course of action”, Organizational Behavior and Human Performance 16, pp. 2744

Velleman, J. D. 1985, “Practical Reflection”, Philosophical Review 94, pp. 33-61 
Whyte, G. 1986, "Escalating Commitment to a Course of Action: A Reinterpretation”, Academy of Management Review 11,pp. 311-321 